\title{
PENGARUH KUALITAS PELAYANAN DALAM PENANGGULANGAN PRA-KRISIS KASUS DI MEDIA SOSIAL TERHADAP CITRA PT KCI
}

\section{The Influence of Service Quality in Preventing Pre-Crisis Case through Social Media Towards the Image of PT KCI}

\author{
Anita Savitri Arfahsita ${ }^{1, *)}$, Muthia Handayani, Nabila Jafani Ladybo \\ ${ }^{1}$ The London School of Public Relations Jakarta, Jakarta 10220, Indonesia \\ ${ }^{*}$ E-mail: anitaarfahsita@gmail.com

\section{ABSTRACT}

This study aims to determine the effect of service quality in handling pre-crisis cases through social media on the image of PT KCI. The method used is a quantitative method using a semantic differential scale. The analytical method used is a simple linear regression analysis method. The results showed that commuter line users assessed the quality of service in handling crisis provided by PT KCI. The empathy variable is a concept that plays an important role in determining the company's image in crisis communication. The implication of this research is that companies need to maintain and improve service quality in handling crisis on social media so that the company's image improves. In the context of development communication, companies need to have empathy for users in order to be able to carry out effective crisis communication.

Keywords: company image, crisis communication, public services, service quality, social media

\begin{abstract}
ABSTRAK
Penelitian ini bertujuan untuk mengetahui pengaruh kualitas pelayanan dalam penanggulangan pra-krisis kasus melalui media sosial terhadap citra PT KCI. Metode yang digunakan adalah metode kuantitatif dengan menggunakan skala semantic differential. Metode analisis yang digunakan adalah metode analisis regresi linier sederhana. Hasil penelitian menunjukkan, pengguna commuter line menilai kualitas pelayanan dalam penanganan krisis yang diberikan PT KCI baik. Variabel empathy merupakan konsep yang berperan penting dalam menentukan citra perusahaan dalam komunikasi krisis. Implikasi pada penelitian ini adalah perusahaan perlu menjaga dan meningkatkan kualitas pelayanan dalam penanganan krisis di media sosial agar citra perusahaan meningkat. Dalam konteks komunikasi pembangunan, perusahaan perlu memiliki empati terhadap pengguna agar bisa melakukan komunikasi krisis yang efektif.
\end{abstract}

Kata Kunci: citra perusahaan, komunikasi krisis, kualitas pelayanan, media sosial, pelayanan publik 


\section{PENDAHULUAN}

Transportasi adalah salah satu kebutuhan mendasar bagi pertumbuhan dan perkembangan masyarakat. Pemerintah memiliki andil besar untuk memenuhi kebutuhan transportasi dengan baik, dengan menyediakan berbagai macam moda transportasi. Beragamnya jenis transportasi di era modern ini membuat masyarakat mempunyai banyak pilihan, sesuai dengan kepentingan dan efisiensi waktu yang diinginkan. Salah satu transportasi yang banyak dipilih oleh masyarakat adalah kereta commuter line. Kerta commuter line dikelola oleh sebuah perusahaan yang bernama PT Kereta Commuter Indonesia (PT KCI) yang merupakan anak perusahaan dari PT Kereta Api Indonesia (PT KAI), sebagai salah satu transportasi umum untuk mengatasi masalah kemacetan di daerah Jabodetabek.

Perusahaan transportasi pada umumnya sering menemukan situasi-situasi krisis seperti tidak berfungsinya sarana dan prasarna, misalnya AC mati, adanya keterlambatan keberangkatan kereta dikarenakan sinyal atau pergantian rel, keterlambatan karena kereta mengalami gangguan teknis dan membutuhkan pengecekan, kereta anjlok bahkan terguling yang membuat perjalanan kereta lain terganggu, dan kecelakaan akibat tabrakan yang terjadi antara kereta dan dengan moda transportasi lainnya yang membutuhkan evakuasi hingga kebakaran di stasiun kereta. Kondisi ini disebut sebagai kondisi krisis, dimana "sebuah event atau peristiwa yang tidak diharapkan dan memiliki dampak bagi organisasi” (Kriyantono, 2015). Dijelaskan pula adanya istilah pre-krisis yang merupakan kegiatan atau aktivitas untuk mencegah suatu krisis terjadi dan mempersiapkan manajemen krisis sebuah perusahaan (Coombs \& Holladay, 2010)

Perusahaan pada umumnya harus memiliki kemampuan manajemen krisis. Terutama pada era new media dan social media, perusahaan harus memberikan respon dengan segera begitu krisis terjadi, dengan pesan yang terbuka dan jujur kepada para pemangku kepentingan (stakeholder) baik itu yang terpengaruh secara langsung atau tidak langsung (Prastya, 2011) atau "crisis management is communicating clear message in fast changing situation or emergency" (manajemen krisis adalah mengkomunikasi pesan yang jelas pada situasi yang cepat berubah atau keadaan darurat) (Tench \& Yeomans, 2017). Komunikasi krisis menjadi penting bagi PT KCI untuk melayani pengguna commuter line. Ada tiga prinsip utama dari komunikasi krisis, yakni: menyampaikan pesan dengan cepat atau segera, konsisten dan terbuka (Coombs, 2006). Coombs menyatakan bahwa tidak memiliki kemampuan komunikasi krisis membuat reputasi perusahaan terancam. Pada studi komunikasi krisis, para ahli menyatakan bahwa komunikasi perlu dilakukan dalam bentuk dialog. Banks (2011) menyatakan bahwa komunikasi krisis adalah dialog antara perusahaan dan publik, sebelum, saat, dan setelah kejadian negatif terjadi. Dialog ini harus melibatkan strategi dan taktik yang detil untuk meminimalisir rusaknya citra perusahaan atau organisasi. Strategi tersebut beberapa diantaranya adalah cepat memberi respon; memberikan informasi yang jujur; perusahaan selalu informatif; perusahaan harus berempati; dan perusahaan memelihara hubungan baik (Firsan, 2011).

Perkembangan teknologi informasi berupa media sosial ini dapat membuka peluang inisiatif lembaga pemerintah dan dunia usaha untuk memanfaatkan internet untuk kepentingan mengakses informasi, mengunggah informasi, mempromosikan dan mengkomunikasikan data (Rusadi, 2014). Media sosial dapat menjadi salah satu alat yang efektif dalam melakukan komunikasi risiko kepada publik. Saat ini, PT KAI dan PT KCI telah menggunakan twitter sebagai media sosialnya, dengan nama akun@KAI121 dan @commuterline. Penggunaan media sosial ini menjadi relevan dalam komunikasi pembangunan, karena perusahaan berusaha untuk berdialog dengan pelanggannya melalui sosial media.

Rusadi (2014) membahas model komunikasi pembangunan partisipatif yang menyatakan bahwa dalam proses pembangunan dibutuhkan keterlibatan berbagai pihak. Termasuk diantaranya adalah masyarakat, bukan hanya dari pemerintah atau perusahaan saja. PT KCI yang merupakan penyedia jasa transportasi membutuhkan keterlibatan penumpang atau masyarakat dalam memperbaiki layanannya. Melaui media sosial, PT KCI tidak mampu menyebarkan informasi kepada pengguna, namun juga memungkinkan para pengguna untuk menyampaikan keluhan dan saran. Twitter yang bersifat real-time dan identik dengan 'what's happening' membuat penggunanya lebih senang untuk mengajukan komplain karena akan dibalas (Aria, 2017). Fenomena ini mampu memperlihatkan 
bahwa media sosial digunakan sebagai salah satu alat dalam melakukan komunikasi krisis, karena memungkinkan pengguna merepresentasikan dirinya maupun berintraksi, bekerja sama, berbagi, berkomunikasi dengan pengguna lain, dan membentuk ikatan sosial secara virtual (Nasrullah, 2017). Media sosial, membuat adanya sosialisasi tiada batas yang seakan mendorong manusia untuk tampil lebih eksis, misalnya ikut ambil bagian dalam trending topic baik dalam komentar maupun status yang memuat pendapat pribadi (Marcello, 2017).

Mengelola media sosial sebagai salah satu strategi komunikasi risiko juga berhubungan erat dengan kualitas pelayanan yang bermakna suatu kegiatan atau urutan kegiatan yang terjadi dalam interaksi langsung antar seseorang dengan orang lain atau mesin secara fisik, dan menyediakan kepuasan pelanggan (Sinambella, 2006). Definisi konvensional dari kualitas biasanya menggambarkan karakteristik langsung dari suatu produk, seperti: kinerja (perfomance), keandalan (reliability), mudah dalam penggunaan (ease of use) estetika (esthetics) dan sebagainya. Adapun dalam definisi strategis dinyatakan bahwa kualitas adalah segala sesuatu yang mampu memenuhi keinginan atau kebutuhan pelanggan (meeting the needs of customers) (Sinambella, 2006). Untuk mengukur bagaimana PT KCI melakukan pelayanan publik atau menentukan kualitas pelayanannya, tulisan ini menggunakan lima indikator pelayanan publik, yaitu: (1) realibility, ditandai dengan pemberian pelayanan yang benar; (2) tangibles, ditandai dengan penyediaan yang memadai sumber daya manusia dan sumber daya lainnya; (3) responsiveness, ditandai dengan keinginan melayani konsumen dengan cepat; (4) assurance, ditandai dengan tingkat perhatian terhadap etika dan moral dalam memberikan pelayanan; dan (5) empathy, ditandai dengan tingkat kemauan untuk mengetahui keinginan dan kebutuhan konsumen.

Seperti yang dijelaskan sebelumnya reputasi perusahaan akan terancam apabila komunikasi krisiti tidak dilakukan dengan baik. Reputasi seringkali berkenaan dengan citra. Kottler menjelaskan bahwa citra adalah respons konsumen yang didefinisikan sebagai kepercayaan (Kottler, 2000). Sementara itu, menurut Nguyen \& Leblanc (2001), citra perusahaan adalah keseluruhan kesan yang terbentuk di benak masyarakat. Jadi citra adalah salah satu aset penting dari organisasi yang selayaknya terus menerus dipelihara" (Gassing \& Suryanto, 2016). Dapat disimpulkan secara umum, citra diartikan sebagai kesan seseorang atau individu tentang sesuatu yang muncul sebagai hasil dari pengetahuan dan pengalamannya (Soemirat \& Ardianto, 2002). Terdapat enam jenis citra, yaitu: (1) citra bayangan (mirror image) adalah pandangan orang dalam perusahaan mengenai pandangan masyarakat terhadap organisasinya. Sering kali citra ini tidak tepat karena kurangnya informasi; (2) citra yang berlaku (current image) merupakan kebalikan dari citra bayangan, yaitu pandangan orang luar mengenai suatu organisasi, citra ini pun belum tentu sesuai dengan kenyataan dan biasanya cenderung negatif; dan (3) citra perusahaan (corporate image) yang merupakan citra dari suatu organisasi secara keseluruhan (Firsan, 2011).

Pembentukan citra dimulai dengan adanya stimulus/rangsangan dalam bentuk infromasi yang berasal dari luar dan menggambarkan proses pembentukan citra. Stimulus ini mendorong terbentuknya presepsi, kognisi, sikap, dan motivasi. Presepsi adalah hasil pengamatan terhadap unsur lingkungan dikaitkan dengan suatu pemahaman, kognisi adalah sspek pengetahuan yang beruhubungan dengan kepercayaan, ide dan konsep, sikap adalah hasil evaluasi negatif atau positif terhadap konsekuensi-konsekuensi penggunaan suatu objek, dan motivasi adalah kecenderungan yang menetap untuk mencapai tujuan tertentu dan untuk sedapat mungkin menjadi kondisi kepuasan maksimal bagi individu pada setiap saat. Proses pembentukan presepsi, kognisi, sikap, dan motivasi inilah yang akhirnya memunculkan respons/perilaku (Ardianto \& Machfudz, 2011; Gassing \& Suryanto, 2016).

Media sosial membuka kesempatan bagi perusahaan untuk membangun citra positif, dimana media sosial memungkinkan perubahan model komunikasi one-to-many menjadi many-to-many. Penggunaan media sosial ini juga memberikan ruang bagi audiens untuk mengekspresikan pendapat dan memberi kesempatan pada perusahaan untuk menggunakan pendapat tersebut sebagai dasar untuk membuat taktik dalam praktik public relations. (Kuvykaite \& Piligrimiene, 2003; White, 2012)

Penelitian terdahulu menunjukkan bahwa pemanfaatan media sosial dengan menggunakan hashtag atau tagar sebagai strategi komunikasi risiko dapat memperbaiki citra perusahaan (Carlina \& 
Paramita, 2017). Penelitian lainnya juga menunjukkan bahwa penggunaan twitter sebagai alat dalam komunikasi risko memberikan sentuhan lebih personal. Kedekatan antara perusahaan dengan pengguna membuat perusahaan lebih percaya diri dalam mengungkapkan fakta serta melakukan konfirmasi atas krisis yang terjadi. Dampak dari kedekatan personal adalah menarik pengguna atau konsumen baru yang rata-rata berasal dari pengguna twitter (Wigley \& Zhang, 2011). Sesuai dengan temuan ini, Solis (2010) menyebutkan terdapat empat C dalam penggunaan media sosial, yaitu: context yang menjelaskan bagaimana cara membingkai sebuah pesan (informasi) dengan memperhatikan penggunaan bahasa maupun isi dari pesan yang akan disampaikan. Selanjutnya communication yang menjelaskan bagaimana berbagi pesan (informasi) seperti mendengar, merespon dan berkembang dengan berbagai macam cara agar pengguna merasa nyaman dan pesan tersampaikan dengan baik. Ketiga adalah collaboration yaitu cara kedua belah pihak bekerja sama untuk membuat segala hal menjadi lebih baik. Dan yang terakhir adalah connection yaitu cara untuk memelihara hubungan yang telah terbina. Empat hal ini dapat membuat pengguna menjadi lebih dekat dengan perusahaan.

Berbeda dari tiga penelitian di atas, penelitian ini menambahkan konsep kualitas pelayanan di media sosial sebagai bagian dari komunikasi krisis, demi meningkatkan citra PT KCI. Tulisan ini ingin mengeksplorasi pengaruh dari kualitas pelayanan dalam penanggulangan pra-krisis yang diberikan di media sosial terhadap citra PT KCI. Tujuan dari penelitian ini terbagi atas tiga, yaitu: (1) mengetahui adanya pengaruh kualitas pelayanan dalam penanggulangan pra-krisis kasus di media sosial terhadap citra PT KCI; (2) mengetahui penilaian pelanggan terhadap kualitas pelayanan dalam penanggulangan pra-krisis kasus di media sosial oleh PT KCI; dan (3) mengetahui bagaimana pandangan pelanggan terhadap citra PT KCI. Penelitian ini mengkombinasikan konsep citra, krisis, pelayanan publik sebagai salah satu bentuk komunikasi pembangunan. Komunikasi pembangunan sendiri bisa didefinisikan proses penyebaran pesan oleh seseorang atau sekelompok orang kepada khalayak guna mengubah sikap, pendapat, dan perilakunya dalam rangka meningkatkan kesejahteraan banyak orang (Kholil, Sahrul, \& Diaurrahman, 2017).

Adapun hipotesis dari penelitian ini adalah:

Ho : tidak ada pengaruh antara kualitas pelayanan dalam penanggulangan pra-krisis kasus di media sosial terhadap citra PT KCI.

Ha: ada pengaruh antara kualitas pelayanan dalam penanggulangan pra-krisis kasus di media sosial terhadap citra PT KCI.

\section{METODE}

Paradigma yang digunakan dalam penelitian ini adalah paradigma positivistik atau ilmu sosial positivis. Neuman (2013) menyatakan bahwa ilmu sosial positivis adalah metode yang terorganisir yang menggabungkan logika deduktif dengan pengamatan empiris yang tepat agar bisa menemukan dan menegaskan seperangkat hukum sebab akibat (kausal) probabilistik, yang dapat digunakan untuk memprediksi pola umum dari aktivitas manusia.

Penelitian ini dilakukan pada bulan Mei 2018 di kampus IISIP Jakarta, responden berpartisipasi langsung dalam pengisian kuisioner. Penelitian ini menggunakan metodologi kuantitatif dimana teknik pengumpulan datanya menggunakan survei dengan membagikan kuisioner kepada sampel untuk mendapatkan informasi serta menjawab pertanyaan penelitian. Dalam penelitian ini hanya terdapat dua variabel; variabel $\mathrm{X}$ (variabel bebas) yaitu kualitas pelayanan dalam penanggulangan pra-krisis kasus di media sosial dan variabel Y (variabel terikat) yaitu citra PT KCI.

Populasi pada penelitian ini adalah mahasiswa IISIP - Jakarta. Populasi yang menjadi target peneliti adalah mahasiswa IISIP - Jakarta jurusan ilmu jurnalistik angkatan 2014 jumlah populasi yang diambil adalah sebanyak 201 mahasiswa jurusan ilmu jurnalistik. 


\section{Operasionalisasi Variabel}

Tabel 1. Operasionalisasi Variabel X dan Y

\begin{tabular}{lll}
\hline \multicolumn{1}{c}{ Variabel } & \multicolumn{2}{c}{ Dimensi } \\
\hline Kualitas Pelayanan dalam Penanggulangan Pra- & 1. Cepat memberi respon (responsivenes) \\
Krisis Kasus di media sosial (X) & 2. Pemberian pelayanan yang handal \\
& (reliability) & \\
& 3. Penyediaan sumber daya manusia dan \\
& lainnya (tangibles) \\
& 4. Tingkat perhatian terhadap etika dan moral \\
& (assurance) \\
Citra PT KCI (Y) Empati (empathy) & \\
& 1. Dimensi \\
& 2. Citra yang berlaku \\
& 3. Citra yang diharapkan \\
& 4. Citra perusahaan \\
\hline
\end{tabular}

Penelitian ini menggunakan teknik sampling purposif (purposive sampling), dimana peneliti dengan sengaja memlih responden yang sesuai dengan kriteria yang telah ditetapkan dan tujuan penelitian. Kriterianya adalah mahasiswa Institut Ilmu Sosial dan Ilmu Politik (IISIP)-Jakarta yang menggunakan commuterline sehari-hari, mempunyai akun twitter, dan pernah atau sering berinteraksi dengan akun twitter KCI. Jumlah sampel yang diambil, dihitung menggunakan rumus Slovin (Siregar 2013 p.34):

$$
n=\frac{N}{1+N(e)^{2}}
$$

Keterangan:

$\mathrm{N}=$ ukuran populasi

$\mathrm{n}=$ ukuran sampel

$\mathrm{e}=$ kesalahan pengambilan sampel yang dapat ditolerir $(10 \%)$

Berdasarkan perhitungan yang sudah dilakukan maka jumlah sampel dalam penelitian ini adalah sebanyak 66 mahasiswa di IISIP-Jakarta Jurusan Ilmu Jurnalistik dan merupakan pengguna KRL commuterline.

Sumber data primer dalam penelitian ini adalah kuisioner dengan skala penelitian semantic diferential, sedangkan data sekunder diperoleh dari jurnal penelitian sebelumnya, buku, dan pencarian literatur secara daring. Hasil uji validitas menunjukkan bahwa rHasil lebih besar dari rTabel yaitu 0,30 dan uji realibilitas terhadap variabel $\mathrm{X}$ dan $\mathrm{Y}$ dinyatakan valid dan reliabel.

Tabel 2. Hasil Uji Reliabilitas Variabel X Pre-test

\begin{tabular}{cc}
\hline $\begin{array}{c}\text { Cronbach's } \\
\text { Alpha }\end{array}$ & N of Items \\
\hline 910 & 15 \\
\hline
\end{tabular}

Tabel 3. Hasil Uji Reliabilitas Variabel Y Pre-test

\begin{tabular}{cc}
\hline $\begin{array}{c}\text { Cronbach's } \\
\text { Alpha }\end{array}$ & N of Items \\
\hline, 954 & 9 \\
\hline
\end{tabular}




\section{HASIL DAN PEMBAHASAN}

Kuisioner dibagikan kepada 66 responden yang menggunakan jasa transportasi KRL untuk kegiatan sehari-hari. Penelitian ini menggabungkan konsep kualitas pelayanan (X) dengan indikator pelayanan publik milik Fitzsimmons dan Fitzsimmons (1997) yaitu; responsiveness, reliability, tangibles, assurance dan empathy. Kemudian indikator pelayanan publik tersebut dikaitkan terhadap citra perusahaan (Y) PT KCI, jenis citra menurut Firsan (2011) yang digunakan citra yang berlaku, citra yang diharapkan dan citra perusahaan.

Uji validitas yang dilakukan pada variable X (kualitas pelayanan) dan variable $\mathrm{Y}$ (citra perusahaan) pada setiap pertanyaan dalam penelitian ini yaitu 0,30 . Hal ini menunjukkan bahwa seluruh peryanyaan dinyatakan valid. Berdasarkan hasil uji reliabilitas, nilai Cronbach's Alpha untuk terdapat 15 pertanyaan pada kuisioner untuk menguji variabel $X$ adalah 0,910 . Sedangkan untuk uji reliabilitas pada 9 pertanyaan pada kuisioner untuk menguji variable $\mathrm{Y}$ adalah 0,954 . Sehingga dengan nilai Cronbach's Alpha > 0,900 maka dapat disimpulkan bahwa pertanyaan variabel X dalam penelitian ini reliabel.

Analisis berdasarkan variabel $\mathrm{X}$ (kualitas pelayanan) yang pertama adalah kecepatan (responsiveness). PT KCI dianggap cepat dalam memberikan informasi dan juga menjawab pertanyaan pelanggan pada akun twitternya. Alat transportasi KRL dianggap salah satu moda transportasi yang paling efisien dan menghemat waktu karena memiliki jalur sendiri, oleh karena itu ketika gangguan terjadi pihak KCI harus dengan cepat memberikan informasi kepada penumpangnya.

Terdapat berbagai informasi yang setiap saat harus diperbaharui oleh PT KCI, baik itu jadwal keberangkatan hingga gangguan yang terjadi. Hal ini termasuk dalam kategori memberikan pelayanan yang handal (reliability). Responden menyatakan informasi yang diberikan sudah cukup jelas. Terdapat berbagai macam informasi yang diinginkan oleh penumpang misalnya, ketika terjadi gangguan penumpang ingin mengetahui berapa lama waktu yang dibutuhkan untuk memperbaiki hal tersebut, kapan kereta berikutnya akan datang, atau apakah mungkin penumpang menunggu apabila gangguan terjadi. Menurut responden PT KCI sudah jelas dalam menjawab estimasi waktu tersebut.

Penyediaan sumber daya dan manusia (tangible) juga merupakan salah satu aspek penting dalam pemberian pelayanan. Menurut responden penempatan petugas di dalam stasiun sudah memadai, selain itu tersedianya papan pengumuman juga dianggap jelas dalam menampilkan informasi yang dibutuhkan penumpang. Secara keseluruhan responden menilai fasilitas yang ada di stasiun sudah cukup memadai.

Ketika terjadi gangguan pada KRL, PT KCI harus memberikan perhatian terhadap etika dan moral (assurance) ketika menanggapi masalah yang ada. Pemberian jaminan seperti kereta tambahan atau pergantian kereta dinilai responden masih belum cukup sering diberikan oleh PT KCI. Menunjukkan rasa kepedulian (empathy) kepada penumpang saat terjadi gangguan juga merupakan hal penting dalam memberikan pelayanan. PT KCI dianggap biasa saja atau belum cukp peka dalam menganggapi keluhan penumpang. Hal ini dikarenakan respon yang diberikan kepada satu penumpang dan penumpang lain sama atau sebagaimana prosedur operasi standar yang berlaku yang membuat kata-kata yang digunakan terkesan kaku dan kurang menunjukkan kepedulian kepada penumpang. Responden juga menilai bahwa PT KCI belum maksimal dalam mengetahui keinginan dan kebutuhan penumpang.

Analisis berdasarkan dimensi variable $\mathrm{X}$ yaitu rata-rata dimensi tangible sebesar 2,55, dimensi responsiveness sebesar 2,36, dimensi reliability sebesar 2,45, dimensi assurance sebesar 2,29 dan dimensi empathy sebesar 2,38. Dapat disimpulkan bahwa dimensi tangible masih dinilai sebagai bagian yang sangat penting dari penanganan krisis atau penyediaan pelayanan, sedangkan assurance dinilai masih rendah dalam penanganan krisis oleh PT KCI.

Analisis variabel Y (citra) yang pertama adalah kategori citra yang berlaku. PT KCI dinilai sudah cukup baik dari segi pelayanan baik teknis maupun non-teknis. Interaksi akun twitter PT KCI 
dengan penumpang, dinilai sudah cukup cepat, karena kecepatan dalam interaksi yang berjalan dibutuhkan penumpang untuk mengetahui informasi terbaru. Responden menilai petugas yang memberikan pelayanan sudah cukup profesional, baik petugas yang bertugas di stasiun maupun di twitter. Berikutnya, kategori citra yang diharapkan, responden menilai PT KCI telah melakukan inovasi dalam membangun citranya sehingga dianggap sudah baik dan sesuai dengan perkembangan jaman. Prestasi PT KCI juga dianggap gemilang oleh responden dan pelayanan dianggap sudah memuaskan. Sebagai sebuah organisasi, citra PT KCI dianggap baik oleh mayoritas responden. Kontribusi staff perusahaan juga perlukan dalam menangani masalah atau gangguan dan respond menilai staff PT KCI sudah aktif dalam merespon masalah. Responden juga menilai informasi di media sosial sudah informatif.

Analisis dimensi variable $\mathrm{Y}$ adalah rata-rata dimensi citra yang berlaku sebesar 2,61, dimensi citra yang diharapkan sebesar 2,66, dan dimensi citra perusahaan sebesar 2,68. Dapat disimpulkan bahwa dimensi citra perusahaan dinilai sebagai bagian yang sangat penting dalam citra PT KCI.

Hasil uji korelasi yang dilakukan untuk variabel $\mathrm{X}$ (penanggulangan pra-krisis; tangible, responsiveness, reliability, assurance dan empathy) dan variabel Y (citra) menghasilkan nilai signifikansi sebesar 0,000 , yang berarti nilai signifikansi $0,000<0,05$. Hal ini menunjukkan adanya hubungan positif antara variabel X (kualitas pelayanan) dengan variabel Y (citra). Hasil tersebut juga menunjukkan bahwa Ho ditolak dan Ha diterima. Begitu juga dengan hasil Uji Anova juga menunjukkan hasil Ho ditolak dan Ha diterima.

Uji Analisis Korelasi Sederhana menunjukkan nilai R (koefisien korelasi) masing-masing dimensi variabel $\mathrm{X}$ adalah 0,856 , selain itu nilai $\mathrm{R}$ square (koefisien determenasi) variabel $\mathrm{X}$ (kualitas pelayanan) memiliki kontribusi sebesar $73,2 \%$ terhadap variabel Y (citra), sedangkan sisanya 26,8\% dipengaruhi oleh faktor lain di luar variabel X.

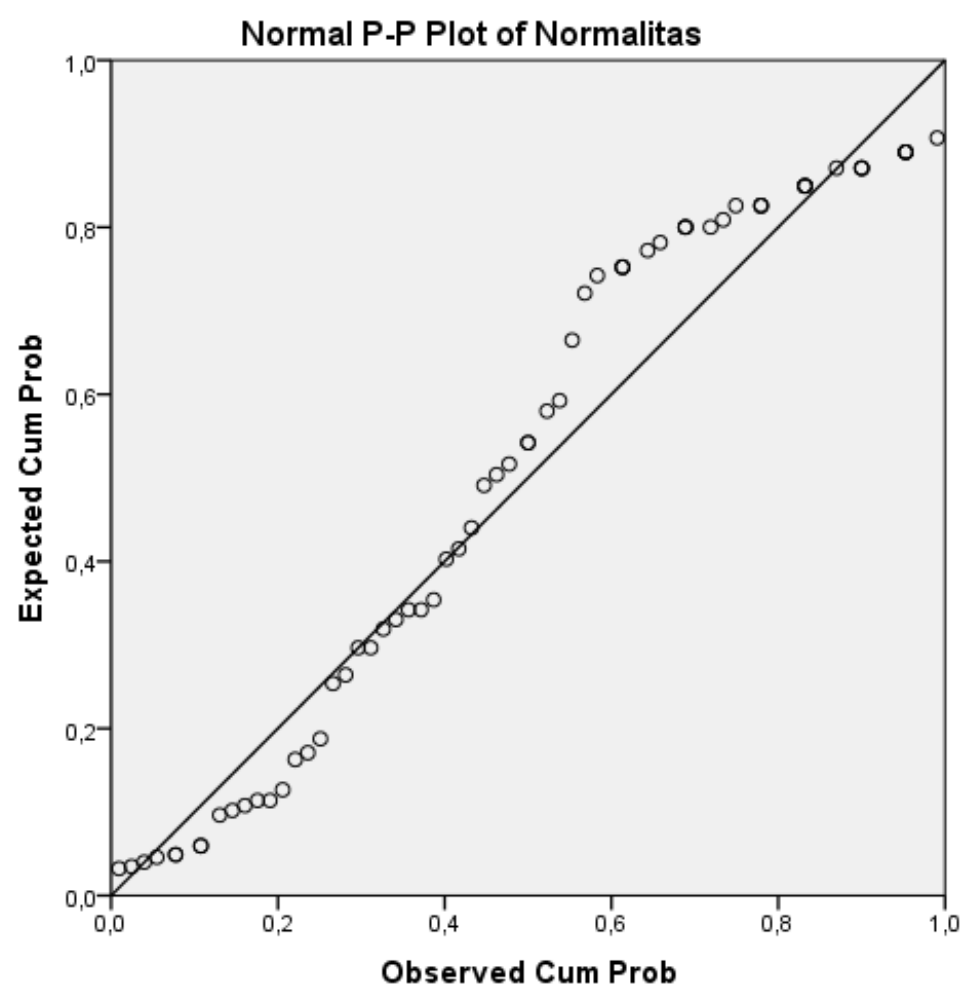

Gambar 1. Uji Normalitas, Data Olahan Peneliti, 2018

Grafik di atas data menyebar di area garis diagonal dan mengikuti arah garis diagonal. Penyebaran data berada tidak jauh dari garis, maka dari itu data yang diperoleh dinyatakan 
berdistribusi dengan normal, diperoleh nilai signifikansi sebesar 0,052>0,05, sehingga model regresi memenuhi asumsi normalitas.

Hasil analisis data menunjukkan bahwa kualitas pelayanan dalam penanggulangan pra-krisis berpengaruh positif dan cukup terhadap citra. Faktor yang memiliki pengaruh paling besar adalah tangible. Tangible (berwujud) meliputi penampilan fasilitas fisik, peralatan, pegawai, dan material yang dipasang (Parasuraman, Zeithaml, \& Berry, 1988). Dimensi ini menggambarkan wujud secara fisik dan layanan yang akan diterima oleh konsumen. Oleh karena itu, penting bagi perusahaan untuk memberikan impresi yang positif terhadap kualitas layanan yang diberika. Menurut penggunanya, aspek tangible dalam kualitas pelayanan yang diberikan oleh PT KCI sudah cukup baik.

\section{KESIMPULAN}

Dari penelitian yang telah dilakukan, ditemukan adanya pengaruh yang cukup kuat antara kualitas pelayanan dalam penanganan krisis terhadap citra PT KCI, dimana $R$ Square yang diperoleh untuk masing-masing dimensi yaitu tangible sebesar 35,5\%, responsiveness sebesar 49\%, reliability sebesar $57 \%$, assurance sebesar 63,6\% dan empathy sebesar 67\%. Dimensi empathy menjadi faktor yang paling tinggi pengaruhnya dari kualitas pelayanan dalam penanganan krisis terhadap citra PT KCI. Sebaliknya, tangible menjadi faktor yang berpengaruh paling rendah. Citra perusahaan dinilai sudah baik oleh penggunanya, sedangkan citra yang berlaku masih kurang baik menurut penggunanya.

Hasil penelitian ini menunjukkan bahwa kualitas pelayanan mempunyai pengaruh yang cukup signifikan dalam penanganan krisis yang berdampak pada pengelolaan citra perusahaan PT KCI. Menurut penilaian pelanggan, kualitas pelayanan PT KCI dalam penanggulangan pra-krisis di media sosial sudah cukup baik. Adanya kegiatan komunikasi krisis yang dilakukan oleh PT KCI memberikan dampak positif kepada citra perusahaan. Kegiatan komunikasi krisis yang dilakukan secara cepat tanggap oleh PT KCI membuat para pemangku kepentingan dengan mudah mendapatkan informasi terkait krisis sehingga hal ini meminimalisir asumsi yang mungkin ditimbulkan oleh krisis yang terjadi. Konsep empati juga menjadi bagian dari strategi komunikasi krisis yang paling penting. Penggunaan empati membuat pelanggan lebih merasa dipahami kebutuhannya saat kondisi pre-krisis bermunculan.

Saran yang dapat diberikan kepada PT KCI adalah untuk memperhatikan penanggulan prakrisis dari segi assurance, sehingga akan lebih baik jika PT KCI memberi jaminan informasi yang pasti mengenai armada keretanya jika terjadi gangguan. PT KCI juga perlu mencari solusi dalam meminimalisir masalah, misalnya pada antrian masuk kereta ke stasiun agar tidak terjadi pergantian rel yang terlalu lama, sehingga para penumpang tidak perlu menunggu lama. Selain itu, kepastian akan informasi yang diberikan juga harus ditingkatkan. Tangible sebagai aspek yang dinilai paling baik dalam kualitas pelayanan, artinya perlu dilakukannya perawatan dan pembaruan untuk fasilitasfasilitas yang ada juga peningkatan keefektifan dan kualitas kinerja staff PT KCI dalam membantu pengguna commuterline. Pada citra perusahaan, PT KCI diharapkan dapat terus memaksimalkan pemberian pelayanan kepada penumpangnya, baik dalam penanggulangan pra-krisis maupun komunikasi sehari-hari dengan penumpang. Sedangkan untuk memperbaiki citra yang berlaku, PT KCI diharapkan dapat meningkatkan lagi dalam memberi pelayanan dalam penanggulangan prakrisis. Meningkatkan komunikasi dan interaksi dapat menjadi cara untuk memperbaiki penilaian penumpang mengenai citra yang berlaku.

\section{DAFTAR PUSTAKA}

Ardianto, E., \& Machfudz, D. (2011). Efek Kedermawanan Pebisnis dan CSR. Jakarta: PT Elex Media Komputindo.

Aria, B. (2017). Pengguna Twitter di Indonesia Dianggap Paling Mahir. Retrieved May 3, 2019, from Viva.co.id website: https://www.viva.co.id/digital/digilife/911575-pengguna-twitter-di-indonesiadianggap-paling-mahir 
Banks, K. F. (2011). Crisis Communications - A Casebook Approach. United Kingdom: Routledge. Carlina, G., \& Paramita, S. (2017). PR Crisis Melalui Media Sosial. Jurnal Komunikasi, 9(1), 81. https://doi.org/10.24912/jk.v9i1.211

Coombs, W. ., \& Holladay, S. . (2010). The Handbook of Crisis Communication. United Kingdom: Blackwell Publishing.

Coombs, W. T. (2006). The Protective Powers of Crisis Response Strategies: Managing Reputational Assets During a Crisis. Journal of Promotion Management, 12((3/4)), 39-46. https://doi.org/10.1300/J057v12n03

Firsan, N. (2011). Crisis Public Relations. Jakarta: PT Raja Grafindo Persada.

Fitzsimmons, J. A., \& Fitzsimmons, M. . (1997). Service Management: Operations Strategy, and Information Technology (2nd ed.). New York: Irwin and MccGraw-Hill.

Gassing, S., \& Suryanto. (2016). Public Relations. Yogyakarta: CV. Andi Offset.

Kholil, S., Sahrul, \& Diaurrahman. (2017). Peran Komunikasi Pembangunan Badan Pemberdayaan Masyarakat (BPM) dalam Pembangunan Sosial dan Keagamaan Di Kota Langsa. Al-Balagh, l(2), 291-302.

Kottler, P. (2000). Marketing Management. New Jersey: Prentice Hall.

Kriyantono, R. (2015). Public Relations, Isu \& Crisis Management: Pendekatan Critical Public Relations, Etnografi Krtitis \& Kualitatif. Jakarta: Prenadamedia Group.

Kuvykaite, \& Piligrimiene. (2003). Communication in Social Media for Company's Image Formation. Economics and Management, 18(2).

Marcello. (2017). Sosial Media yang Kini Menjadi War Media.

Nasrullah, R. (2017). Media Sosial Perspektif Komunikasi, Budaya dan Sosioteknologi. Bandung: Simbiosa Rekatama Media.

Neuman, W. L. (2013). Metode Penelitian Sosial: Pendekatan Kualitatif dan Kuantitatif. Jakarta: PT. Index.

Nguyen, N., \& Leblanc, G. (2001). Corporate Image and Corporate Reputation in Customers' Retention Decisions in Services. Journal of Retailing \& Consumer Services, 8, 227-236.

Parasuraman, A., Zeithaml, V. A., \& Berry, L. L. (1988). SERVQUAL: a multiple-item scale for measuring consumer perceptions of service quality. Journal of Retailing, 64(1), 12-37.

Prastya, N. M. (2011). Komunikasi Krisis di Era New Media dan Social Media. Jurnal Komunikasi, 6(1), 1-20.

Rusadi, U. (2014). Makna Dan Model Komunikasi Pembangunan. Jurnal Studi Komunikasi Dan Media, 18(1), 89. https://doi.org/10.31445/jskm.2014.180105

Sinambella. (2006). Reformasi Pelayanan Publik. Jakarta: PT Bumi Aksara.

Soemirat, S., \& Ardianto, E. (2002). Dasar-dasar Public Relations. Bandung: Remaja Rosdakarya.

Solis, B. (2010). Engage! The Complete Guide for Brands and Businesses to Build, Cultivate, and Measure Success in the New Web. New Jersey: John Wiley \& Sons, Inc.

Tench, R., \& Yeomans, L. (2017). Exploring Public Relations: Global Strategic Communication. United Kingdom: Pearson Education Limited.

White, C. M. (2012). Social Media, Crisis Communication, and Emergency Management. Florida: Taylor \& Francis.

Wigley, S., \& Zhang, W. (2011). A Study of PR Practitioners' Use of Social Media in Crisis Planning. Public Relations Journal, 5(3), 1-16. 